\title{
Mexican Forest Fires and their Decadal Variations
}

\author{
Graciela Velasco Herrera ${ }^{a^{*}}$ \\ ${ }^{a}$ Centro de Ciencias Aplicadas y Desarrollo Tecnológico, Universidad Nacional Autónoma \\ de Mé xico, Ciudad Universitaria, C.P. 04510, México DF. Tel: (55) 56228602
}

\begin{abstract}
A high forest fire season of two to three years is regularly observed each decade in Mexican forests. This seems to be related to the presence of the El Niño phenomenon and to the amount of total solar irradiance. In this study, the results of a multi-cross wavelet analysis are reported based on the occurrence of Mexican forest fires, El Niño and the total solar irradiance for the period 1970-2014. The analysis shows that Mexican forest fires and the strongest El Niño phenomena occur mostly around the minima of the solar cycle. This suggests that the total solar irradiance minima provide the appropriate climatological conditions for the occurrence of these forest fires. The next high season for Mexican forest fires could start in the next solar minimum, which will take place between the years 2017 and 2019. A complementary space analysis based on MODIS active fire data for Mexican forest fires from 2005 to 2014 shows that most of these fires occur in cedar and pine forests, on savannas and pasturelands, and in the central jungles of the Atlantic and Pacific coasts.
\end{abstract}

Corresponding author. E-mail address: graciela.velasco@ccadet.unam.mx

(C) 2016. This manuscript version is made available under the Elsevier user license http://www.elsevier.com/open-access/userlicense/1.0/ 


\section{Introduction}

Forest fires have both natural and anthropogenic causes. There are two types of forest fires: 1) surface fires, which spread with a flaming front and burn senescent leaves, twigs, dry grass, leaf litter, fallen branches and other fuels located at ground level and 2) crown fires, in which burning occurs in the top layer of tree foliage and shrubs, often sustained by a surface fire. The latter is the most intense type of fire, often the most difficult to contain, needing strong winds, steep slopes and a heavy fuel load to continue burning. Forest fire behavior is influenced by different factors and their interaction, e.g., fuels, weather conditions and topography. A forest fire requires three elements: heat, oxygen and fuel. These three elements are designated as the "fire triangle" (Barenklau, 2001).

There are different methods of research and mathematical modelling of forest fires, which are used to analyse their prevention (Xodakov and Jarikova, 2011; Grifin, 1981;

Nordemann et al., 2008). In this paper a time-frequency analysis is presented to find the frequency of the low and high Mexican forest fire seasons and also to find possible factors, both external and internal, involved in Mexican forest fires.

\subsection{Mexican Forest Fires}

Figure 1 shows the vegetation in Mexico. It is well known that Mexico has a great deal of biological wealth in its tropical temperate forests and semi-desert climates; it ranks fourth worldwide in importance for the high diversity of its endemic species. This wealth is a national priority, a heritage that must be preserved for its enormous capacity to generate ecological, social and economic benefits. Forests must be protected against one of its most frequent enemies: forest fires (Cibrian et al., 2008).

Of the total Mexican surface area, 139.7 million hectares have some sort of forest cover. Just over $50 \%$ of the forest area corresponds to fire-adapted ecosystems. Almost $36 \%$ corresponds to fire-sensitive ecosystems. Unfortunately, until 2007 Mexico also occupied the eighth place among countries that have lost forests due to forest fires (Juárez-Orozco and Cano-Santana, 2007). Almost 90\% of them are surface fires and many occur during times of increased drought. The causes vary according to the region: in the center of the country, the cause is the burning of pasture and bonfires, whereas, in the southeast the main cause is the slash-and-burn method to prepare natural areas of vegetation for cultivation.

Drought refers mainly to long periods of the lack, scarcity or delay of rainfall and to extended periods of time with below-normal precipitation. Climatic variations on decadal, centennial to millennial timescales are very important in the analysis of historic drought. Using the Palmer Drought Severity Index for southeastern Mexico, Mendoza et al. (2007) 
found a quasi-decadal periodicity for the period of 1921-1987. Hodell et al. (2001) reported a drought frequency of 208 years and suggested that the Maya were affected by this periodicity in precipitation. Mendoza et al. (2006) found the periodicities of 7, 12, 20, 43, and 70 years by using a historical drought catalogue for between 1502 and 1899 in the southeastern part of Mexico.

Around 8900 fires in Mexico occur annually, affecting 27\% of the country's woodlands, other shrubs and grasslands or an average of 327,000 hectares of forests. The areas annually impacted by forest fires and the numbers of events vary widely depending on weather conditions and the social and economic conditions of the affected areas. In general, naturally caused forest fires are an important part of the dynamics of the ecosystems, but it is not the same when these natural disasters are of anthropogenic origin, which unfortunately cause $90 \%$ of these events (Juárez-Orozco and Cano-Santana, 2007). These kinds of fires constitute one of the significant causes of deforestation. Resources to combat them are very limited, significantly decreasing the affected forest areas, thus becoming a major factor in the gestation of a complex environmental problem (Torres, 2004).

One dramatic year, which set the tone, was that of 1998. That year, 14,445 forest fires were recorded, which affected 850,000 hectares. The scale was such that it reached twenty states of the country and some Central American countries; between May 14 and 20 of that year, a thick haze resulted from the particles released by the fires, which spread to the states of Texas and Florida in the USA, where health measures were taken and an environmental alert was decreed (Torres, 2004). Table 1 shows the Mexican states that had the highest incidence of fires during this event. In these states, the weather conditions for this disaster have been attributed to the ENSO phenomenon.

\subsubsection{The solar cycle and its influence on the Earth's climate}

There are many studies that have investigated the existence of a relationship between the solar cycle, climate variability and natural phenomena on Earth. Solar activity is characterized by, among other manifestations, daily, monthly, and yearly periodicities. It is also known that the solar cycle (Schwabe periodicity) varies cyclically with a mean period of about 11 years.

There are many research projects that have studied solar activity: for example, the solar cycle is reviewed in the work of Hathaway (2010). The 11-year cycle of solar activity is characterized by the rise and fall in the number and surface area of sunspots. The author examined a number of other solar activity indicators. They include the $10.7 \mathrm{~cm}$. radio flux, total solar irradiance, the magnetic field, flares and coronal mass ejections, geomagnetic activity, and galactic cosmic ray fluxes, as well as radioisotopes in tree rings and ice cores that vary in their association with sunspots. 
He also examined the characteristics of individual solar cycles, including their maxima and minima cycle periods and amplitudes, cycle shape, and the nature of active latitudes, hemispheres, and longitudes. Additionally, Hathaway (2010) examined long-term variability, including the Gleissberg Cycle and the Gnevyshev-Ohl Rule; short-term variability includes the 154-day periodicity, quasi-biennial variations and double-peaked maxima.

The Sun can influence climate through different mechanisms and periodicities (Scafetta and West, 2005), for example, decadal and secular periodicities. Haigh (2007) reviewed some of the evidence for solar influence on the lower atmosphere and discussed some of the mechanisms, which the Sun can use to produce significant impacts, which could be expected from a single account of changes in total solar irradiance. Velasco and Mendoza (2008) found different climatic phenomena that presented coherence at approximately 11year cycles, the 22-year Hale cycle, and the 60-year Yoshimura-Gleissberg cycle.

Kopp and Lean (2011) assessed the accuracy and stability of irradiance measurements made since 1978 and the implications of instrument uncertainties and instabilities for climate research in comparison with the new Total Irradiance Monitor (TIM) data.

Currie $(1974,1993)$ conducted a study of the solar cycle and surface air temperature and found evidence of a relationship between surface air temperature and solar activity. Over a period of 9-25 years, this author used the maximum entropy Burg method to detect a single signal in surface air temperature for an area of continental extent. Currie (1993) reported the spectrum analysis of 1197 USA air temperature records, yielding evidence for two peaks with periods of $18.8 \pm 1.7$ and $10.4 \pm 0.5$ years. These peaks were identified as the 18.6-year luni-solar cycle and the 10-11 year solar cycle climate signals, induced by the twelfth largest constituent tide acting on the Earth and a variation of 10 to 11 years in the Sun's luminosity of the order of $0.1 \%$. Also, Currie (1974) used Burg's maximum entropy method and showed evidence for the solar cycle signal in the power spectrum of late nineteenth- and twentieth-century surface air temperature data for the North American continent. Nominal amplitude (uncertain by a factor of 2) is $0.1 \mathrm{C}$, with a period of $10.6+$ 0.3 years.

The air surface temperature is a basic meteorological parameter, and its variation is a primary measure of global, regional and local climate changes (Souza Echer et al., 2012). In this study, the authors analyze the averaged global, hemispheric and latitudinal surface air temperature time series and the Sunspot Number $(\mathrm{Rz})$ for the 1880-2005 interval, which was decomposed into frequency bands through wavelet multi-resolution analysis. The authors have proposed that the 22-year magnetic field solar cycle might have a higher effect on the Earth's climate than the solar variations related to the 11-year sunspot cycle. They 
found a very low correlation between the averaged global, hemispheric and latitudinal surface air temperature and sunspot numbers in the 11-year solar cycle band (8-16 years) from 1880 to 1950 . Furthermore, it appears that the 22-year magnetic field solar cycle might have a higher effect on the Earth's climate than the solar variations related to the 11year sunspot cycle.

A phenomenological thermodynamic model was adopted by Scafetta and West (2007) to estimate the relative contribution of the solar-induced versus anthropogenic-added climate forcing during the industrial era. Scafetta and West (2008) contend that the changes in the Earth's average surface temperature are directly linked to two distinctly different aspects of the Sun's dynamics: the short-term statistical fluctuations in the Sun's irradiance and the longer-term solar cycles. Also, Scafetta (2010) reported that the climatic variations on different time-scales could be of astronomical origin. Yousef (2000) suggests that important climatic features such as droughts and unusual growing seasons are dependent on the solar cycle.

Shuyang and Guoyu (1994) studied the relationship between forest fires in China's Heilongjiang Province, solar activity and the sea surface temperature (SST) of the North Pacific Ocean. They found a negative correlation between solar activity and forest fires. The SST in the North Pacific Ocean influenced the occurrence of forest fires and the level of their conditions in Heilongjiang province.

Milenkovic et al. (2011) reported the impact of solar activity on forest fires in Deliblatska peščara, Serbia, for the period 1948-2009, when there were four great forest fires (1973, 1990, 1996 and 2007). Gomes and Radovanovic (2008) analyzed the solar activity as a possible cause of large forest fires in southwestern and southeastern Europe.

\subsection{Mexican Forest Fires Seasons}

A comparison of data from 1998 to 2006 (Figure 2) shows that the fire season coincides with the dry season, which runs mainly from January to May (CENAPRED, 2001). Most forest fires occur throughout the country during the springtime months, although in the northwest, the critical months are July and August (Cibrián et al., 2008).

Between January and May many fires occur. This period coincides with the season of frost and drought when the amount of combustible material is relatively high. Various causes for the number of events during these months have been observed (CENAPRED, 2001).

- January: a very cold month, when a great amount of vegetation is burned by frost.

- February: there is an increase in heat and wind speed. 
- March: a dry environment with strong winds, and areas with a great amount of combustible material left over from previous fires.

- April: temperatures rise, with an increase in average daily fires and drought.

- May: in many states of the country, forest fires coincide with the highest temperatures of the year.

\subsection{El Niño Southern Oscillation (ENSO) and Forest Fires in the Americas}

Becerra and Poveda (2006) have analyzed the temporal dynamics of forest fires; the authors pointed out that this is a challenge because of a close relationship between forest fires and land use, land cover and weather conditions. The analysis of annual and inter-annual temporal variability in the incidence of forest fires provides tools to make inferences about climate processes and feedbacks of phenomena like ENSO at an inter-annual scale. Using the (ATSR) World Fire Atlas (ESA, Europe) database and GOFC/GOLD-Fire software (Monitoring and Mapping Implementation Team), the variability of forest fires in South America is divided into three areas of study: the Amazon rainforest, which includes territory in nine nations: Bolivia, Brazil, Colombia, Ecuador, Guyana, Peru, Suriname, French Guiana and Venezuela; the Rio de la Plata Basin, which includes areas of southeastern Bolivia, southern and central Brazil, the entire country of Paraguay, most of Uruguay, and northern Argentina; and the Colombo-Venezuelan Plains, situated to the east of the Andes in Colombia and Venezuela. This study is done using annual time scales and temporal scaling properties. Forest fires in the Amazon River basin during the period 19972003 are also quantified. Fires in South America exhibit a strong annual cycle associated with the annual cycle of precipitation in each area of study. In addition, the effect of the two phases of the ENSO can be appreciated, with a higher incidence of fires during El Niño and a decrease during La Niña.

Carvajal et al. (1998) discovered some manifestations of the ENSO and its impact on the water resources of the Valle del Cauca (Colombia) during the warm phase (Niño); this is due to a water deficit and during the cold phase (Anti Niño or Niña) to excessive rainfalls. During El Niño episodes, droughts, forest fires, crop and biodegradable products losses, a decline in fishing yields, increased disease, and energy rationing occur; meanwhile, during La Niña periods there is an increased risk of flooding, erosion and the destruction of road infrastructure.

The forest fires that have occurred in Mexico over the years have been attributed to various climate indexes such as the ENSO, especially during the most extreme cases, like the fire of 1998. Kitzberger et al. (2001) have analyzed and compared the fire histories of the southwestern United States (1914 - 1987) and the northern Patagonia region of Argentina (1938-96) and found that both regions share similar relationships of climatic anomalies with the ENSO. 
González-Ramírez et al. (2007) have studied forest fires in Mexico and their relationship with the effects of El Niño. They analyzed the results of a rainfall deficit in 1998 on the area burned (1000 hectares) during extreme events, taking into account fire and rainfall data from the National Forestry Commission and the National Weather Service, respectively. In 1998 - a year with the presence of El Niño - 14,445 forest fires in Mexico affected 849,000 hectares, with more than $50 \%$ of them occurring in southern Mexico. This suggests that the area burned during extreme events could be related to the length of a substantially dry period (15 days), due to the large accumulation of combustible material in wooded areas, mainly in the southern part of the country. In contrast, extreme events are less frequent in the north of the country because the behavior of the rainy season associated with El Niño is different there, and this results in a smaller amount of fuel available and thus fewer, smaller fires. In addition, González-Ramírez et al. (2007) mentioned that it is important to study the effects of El Niño on extreme fires due to its role in strengthening the effects of drought and the anthropic use of fire. Mendoza et al. (2006) reported that $38 \%$ of the droughts in southeastern Mexico are associated with El Niño.

\section{Data and Method}

Different studies have reported the relationship between solar activity and climate. To find the possible relationship between solar activity, forest fires and the ENSO, we have used monthly averaged data in a multi-cross wavelet analysis for the period from 1970 to 2014 .

\subsection{Data}

- The Multivariate ENSO index (MEI) from 1970 to 2014 was used, taken from the website of the National Oceanic and Atmospheric Administration: http://www.esrl.noaa.gov/psd/enso/mei/table.html

- Data on Mexican forest fires for the period from 1970 to 2014 were downloaded from the National Forestry Commission of Mexico (CONAFOR, Comisión Nacional Forestal) website (http://www.conafor.gob.mx/web/).

- Total solar irradiance (TSI) is the primary energy source of the Earth's climate system (Salby, 1995), and, therefore, its variations can contribute to natural climate change (Kopp and Lean, 2011; Scafetta and West, 2005). The instrumental Total Solar Irradiance (TSI) records began to be kept in 1978. There are different composite series: a) the Physikalisch-Meteorologisches Observatorium Davos (PMOD) (Fröhlich, 2006), b) the Royal Meteorological Institute of Belgium (RMIB) (Dewitte et al., 2004), c) the Active Cavity Radiometer Irradiance Monitor (ACRIM) (Willson and Mordvinov, 2003; Scafetta and Willson, 2014), and d) the Total Irradiance Monitor (TIM) (Kopp et al., 2005). These composites employed 
different calibration techniques and mathematical algorithms. In this paper, the new VIRGO scale TSI 42-65-1602 PMOD-composite data from between 1978 and 2014 were used; from 1976-1978 the PMOD-extended data is used; for the periods 19701975 and 2015-2030, the PMOD-reconstruction by Velasco Herrera et al. (2015) was used. Web page of TSI PMOD data:

ftp://ftp.pmodwrc.ch/pub/data/irradiance/composite/DataPlots/ext_composite_42_6 5_1602.dat

- MODIS fire data for detecting Mexican forest fires from 2005 to 2014 were used, web page: http://modis-fire.umd.edu/index.php

\subsection{Method}

The wavelet transform was applied in order to study local variations of spectral power within a time series at multiple periodicities. The Morlet wavelet was used (Torrence and Compo, 1998) and was chosen because it provides a higher periodicity resolution in the complex number domain, allowing us to filter the series in bandwidths (Torrence and Compo, 1998; Soon et al., 2014). The Morlet wavelet, ${ }_{0}($ ), consists of a complex exponential function modulated by a Gaussian and is defined as (Torrence and Compo, 1998):

$$
{ }_{0}()={ }^{\frac{1}{4}} e^{i} e^{2 / 2}
$$

where $\eta$ is a nondimensional "time" (Torrence and Compo, 1998). The Morlet wavelet can be considered as a mother wavelet when it has finite energy and a zero mean (i.e., satisfying the admissibility condition, ${ }_{o}=6$ (Farge, 1992).

The continuous wavelet transform of a discrete sequence $X_{n}$ is defined as the convolution of $X_{n}$ with a scaled and translated version of ${ }_{0}()$.

$$
W_{n}(s)=\sum_{n^{\prime}=0}^{N 1} x_{n^{\prime}} *\left[\frac{\left(n^{\prime} n\right)}{s} t\right]
$$

Torrence and Compo (1998) has defined the wavelet power spectrum as $\left|W_{n}(s)\right|^{2}$, while Norbert Wiener introduced the concept of cross function (Soon et al., 2014). This function allows us to find similarities and differences between two time series: 1) when they have high power in common, and 2) when there is a phase relationship between the two signals. Furthermore, the author states that the wavelet transform is a time series that represents the variance, while the cross wavelet of two series represents the covariance of these signals; therefore, the cross wavelet gives us information regarding to what degree the energies of the two signals are related (Torrence and Compo, 1998).

The multiple-cross-wavelet (MCW) was used to analyze multiple time series and to facilitate the identification of periodic oscillations in the datasets (three time series in the 
current case): a) Mexican forest fires, b) the ENSO, and c) TSI. The MCW ( ${ }_{\text {mow }}$ ) was used to find the similarities and differences between these time series. Soon et al., (2014) define the ${ }_{m c w}$ as:

$$
{ }_{m c w}=W^{X_{1}, X_{2}, X_{3}, \ldots, X_{m}}=\left\langle W_{F_{i}}{ }^{m} W_{G_{k}}^{*}\right\rangle
$$

where $\mathbf{X}_{\mathbf{1}}, \mathbf{X}_{\mathbf{2}}, \mathbf{X}_{\mathbf{3}}, \ldots$, and $\mathbf{X}_{\mathbf{m}}$ are the time series, $\mathrm{F}$ and $\mathrm{G}$ are matrices, and $\langle>$ indicates an average of the MCW. The angle of $W^{X 1, X 2, X 3, \ldots, X m}$ describes the phase relationship between $\mathbf{X}_{\mathbf{1}}, \mathbf{X}_{\mathbf{2}}, \mathbf{X}_{\mathbf{3}}, \ldots$, and $\mathbf{X}_{\mathbf{m}}$ time series (Soon et al., 2014).

The MCW measures the degree of similarity between the system's input and output, as well as the consistency of the output signal based on the input for each frequency component. If the synchronization between time series is high, then the relative phase relationship between the phenomena is shown as arrows in the MCW (figure 6): arrows at $0^{\circ}$ (horizontal right) indicate that all of the phenomena are in phase, and arrows at $180^{\circ}$ (horizontal left) indicate that they are in anti-phase. It is very important to point out that these two cases imply a linear relationship between the considered phenomena; arrows at $90^{\circ}$ and $270^{\circ}$ (pointing vertically up and down, respectively) indicate an out of phase situation, which means that the two phenomena have a non-linear relationship (Soon et al., 2014).

To determine significance levels in the global wavelet spectra, it is necessary that an appropriate background spectrum be used, for example, white noise, with a flat Fourier spectrum, or red noise, to indicate increasing power with decreasing frequency. The red noise model is applied here (Gilman et al., 1963) because it estimates the significance level for each periodicity (a red dotted line with 95\% confidence level in the global wavelet spectra). A model for red noise (Torrence and Compo, 1998) is:

$$
x_{n}=x_{n 1}+z_{n}
$$

The spectral density (Southworth, 1960) of the red noise (Eq. 4) is

$$
P_{n}=\frac{1}{1+{ }^{2} 2 \cos (2 n / N)}
$$

Meaningful periodicities (with a confidence level greater than 95\%) must be inside the cone of influence (COI) that is the region of the wavelet spectrum, outside of which the edge effects become important. 


\section{Results and discussion}

Figures 3, 4 and 5 show the wavelet spectra of Mexican forest fires, the MEI and TSI, respectively. The time series are shown in the top panel. The wavelet powers are shown in the central panel (the COI is the U-shaped curve). The global wavelet is shown in the left panel; the dotted lines are the red-noise level.

The wavelet analysis of Mexican forest fires from 1970 to 2014 (the black bars in the top panel) presented periodicities of $11.02,5.83$ and 2.45 years. The periodicity of 11.02 years could be associated with solar activity (Velasco Herrera et al., 2015). The 5.83 and 2.45 years periodicities may be associated with the ENSO. The spectral analysis of the ENSO (black area in top panel) demonstrates the evolution of the periods from 1970 to 2014. The global wavelets present periodicities of 11.37, 5.2, 3.89, 2.6 and 1.5 years.

The global wavelets of the TSI from 1970 to 2014 present periodicities of 11.02, 5.51, 3.27, 1.94 and 1.03 years. A summary of the main periodicities for the ENSO, TSI, and Mexican forest fires are shown in Table 2.

Using wavelet analysis, Scafetta and West (2005) found the solar signature on global surface temperatures using the ACRIM total solar irradiance satellite composite of Willson and Mordvinov (2003). Also, Rampelotto et al. (2012) used the cross wavelet between rainfall and temperature versus the ENSO and reported periodicities of 2-8 years; the cross wavelet of rainfall and temperature versus sunspot number allowed them to find the periodicity of the solar cycle (11 years). By applying the wavelet analysis of the total annual precipitation falling on Pelotas in southern Brazil, Souza Echer et al. (2008) reported periodicities of around 2-6 years. Scafetta (2009) analyzed the solar contribution to global mean air surface temperature change. For more details on the climate of the Sun and the Earth, see the review by Haigh (2007).

If the wavelet spectrum is calculated individually for the TSI, MEI, and Mexican forest fires, and these spectra show that they have some periodicities in common; this does not necessarily mean there is a physical relationship between them. However, if the global MCW spectrum shows that there are common periodicities, this implies that there is a physical mechanism and/or certain medium connecting these phenomena. It is precisely such frequency synchronization that may indicate that there is coupling, modulation and/or resonance between these phenomena.

Figure 6 shows the results of the MCW analysis of Mexican forest fires (black lines), TSI (blue line) and MEI (red line). The global wavelets present important periodicities of 11.02 and 5.2 years. The local phase (black line) of the decadal periodicity (lower panel) is oscillating around zero, i.e., there is a linear relationship between the three analyzed 
signals. The decadal oscillation (blue line) shows that the decadal dependence is very strong for all three signals. These results demonstrate that it is almost a linear system, except for the 1985-1990 time interval.

Preliminary estimates suggest that the current ENSO (2015-2016) is less intense than the ENSO of 1998. This analysis shows that Mexican forest fires and the strongest El Niño phenomenon occur mostly around the minima of the solar cycle. This suggests that total solar irradiance minima provide appropriate climatological conditions for the occurrence of a high forest fire season.

According to a multiple wavelet analysis showing the connection between forest fires and total solar irradiance, there is a decadal relationship from 1970 to 2014. Besides the estimates of Total Solar Irradiance (Velasco Herrera et al., 2015) shown in Figure 7 for the years between 2015 and 2030 (solar cycle 24-25), using Least Squares Support Vector Machines (Vapnik, 1998; Suykens et al., 2005), decadal estimates for Mexican forest fires for the same period were performed for this study. The next high season of Mexican forest fires will be from the years 2017 to 2019 (the next solar minimum).

In Figure 8, the locations of forest fires (black points) using MODIS satellite images are shown. Mexican forest fires on the Atlantic coastal areas occur primarily in savanna (purple), middle jungle (pink), and cedar and pine forest (green) and on the Pacific coast in pastureland (brown) and middle jungle (pink).

Figures 9 and 10 show the Probability Density Function (PDF, spatial distribution) of the geographic coordinates (longitude and latitude, respectively) of Mexican forest fires using MODIS data (Figure 9). The PDF of the longitudinal coordinate is a bimodal distribution (Figure 9) and that of the latitudinal is multi-modal (Figure 10). The asymmetry in the PDF shows that there is a modulation in Mexican forest fires associated with different factors (solar activity and the ENSO), i.e. Mexican forest fires are not random processes.

In terms of longitude, there are two coordinates where most of the fires are concentrated: $102^{\circ} \mathrm{W}$ and $90^{\circ} 17 \mathrm{~W}$; in terms of latitude, they are $17^{\circ} \mathrm{N}$ and $19^{\circ} \mathrm{N}$. The results of Figures 8 and 9 show two areas in Figure 7 where more than $80 \%$ of the forest fires are located: a) one in the Mexican southeast (on the Atlantic) and b) another in the Mexican southwest (on the Pacific). In addition, more than $80 \%$ of the forest fires in Mexico are of the surface fire variety.

\section{Conclusions}

- A decadal periodicity was found when multi-cross wavelet analysis was applied to the relation between Mexican forest fires, El Niño and Total Solar Irradiance for the 
period from 1970 to 2014, thus making it clear that one of the key external modulators of forest fires is TSI.

- Wavelet analysis shows that the seasons of high activity for Mexican forest fires and the strongest El Niño events occur mostly around the minima of the solar cycle.

- Forecasts and early warnings based solely on the ENSO have been unable to find a pattern that would reduce the risk. Although forest fires are mostly provoked by anthropogenic activities, the season of high (or low) forest fire activity depends on several variables, especially on the accumulation (or reduction) of combustible plant-based fuel, which has mostly natural causes. Therefore, if these modulators have already been identified, then we believe that a spatial analysis would be necessary to identify prone areas before the human factor intervenes, which will introduce new elements for an early warning system upgrade.

- According to the decadal variability of Mexican forest fires and to estimates of solar irradiance for future solar cycles, the next high season of Mexican forest fires could start in the next solar minimum, which will take place between the years 2017 and 2019.

- By using MODIS active fire data for detecting Mexican forest fires from 2005 to 2014, it was found that fires along the Atlantic coast occur primarily in cedar and pine forests, savanna and middle jungle; whereas in the Pacific, they occur in pastureland and middle jungle. More than $80 \%$ of Mexican forest fires are of the surface fire variety.

- The longitudinal spatial distribution is bimodal and the latitudinal is multi-modal. Forest fires in Mexico have occurred in areas between $102^{\circ}$ and $90^{\circ} 17 \mathrm{~W}$ longitude and $17^{\circ} \mathrm{N}$ and $19^{\circ} \mathrm{N}$ latitude.

\section{Acknowledgments}

This work was developed in the Laboratory of Intelligent Systems-CCADET, UNAM and internal project 2012-2014. The author would like to thank three anonymous referees for their valuable and constructive suggestions. The MODIS data set was provided by the University of Maryland and NASA FIRMS operated by NASA/GSFC/ESDIS with funding provided by NASA/HQ. Imagery Map source credits: Esri, DigitalGlobe, GeoEye, i-cubed, Earthstar Geographics, CNES/Airbus DS, USDA, USGS, AEX, Getmapping, Aerogrid, IGN, IGP, swisstopo, and the GIS User Community. 


\section{References}

Barenklau, K., 2001. Agricultural Safety. CRC Press, ISBN 9781566704878.

Becerra, A., Poveda G., 2006. Variabilidad anual e interanual de los incendios forestales en Suramérica y su escalamiento temporal en la Amazonía (Annual and interannual variability of forest fires in South America and their temporal scaling in Amazonia). Meteorol. Colomb. 10, 121-131.

Carvajal, Y., Jiménez, H., Materón H., 1998. Incidencia del fenómeno ENSO en la hidroclimatología del Valle del Río Cauca-Colombia (ENSO impact on the hydroclimatology of the Cauca River Valley, Colombia). Bull. Inst. fr. études andines 27 (3), 743-751.

CENAPRED, 2001. Diagnóstico de Peligros e identificación de Riesgos de Desastres en México. Atlas Nacional de Riesgos de la República Mexicana, México (Diagnosis of hazard and identification of disaster risks in Mexico, National Risk Atlas of Mexico). ISBN 970-628-593-8.

Cibrian, T. J., Martínez, D. R., Raygoza, M. A., 2008. Incendios Forestales (Forest fires). Serie de Fascículos CENAPRED. ISBN 978-607-7558-10-1.

Currie, R.G., 1974. Solar cycle signal in surface air temperature. J. Geophys. Res. 79 (36), 5657-5660. http://dx.doi.org/ 10.1029/JC079i036p05657.

Currie, R.G., 1993. Luni-solar 18.6 and solar cycle 10-11-year signals in USA air temperature records. Int. J. Climatol. 13, 31-50. http://dx.doi.org/ 10.1002/joc.3370130103

Dewitte, S., Crommelynck, D., Joukoff, A., 2004. Total solar irradiance observations from DIARAD/VIRGO. J. Geophys. Res. 109, A02102.

http://dx.doi.org/10.1029/2002JA009694

Farge, M., 1992. Wavelet transforms and their applications to turbulence. Ann. Rev. Fluid Mech. 24, 395-458. http://dx.doi.org/10.1146/annurev.fluid.24.1.395.

Fröhlich, C., 2006. Solar irradiance variability since 1978. Revision of the PMOD composite during solar cycle 21. Space Sci. Rev. 125 (1), 53-65.

http://dx.doi.org/10.1007/s11214-006-9046-5.

Gilman, D.L., Fuglister, F.J., Mitchell Jr., J.M., 1963. On the Power Spectrum of "red noise”. J. Atmos. Sci. 20 (2), 182-184. 
http://dx.doi.org/10.1175/1520-0469(1963)020<0182:OTPSON>2.0.CO;2.

Gomes, J.F.P., Radovanovic, M., 2008. Solar activity as a possible cause of large forest fires - A case study: Analysis of the Portuguese forest fires. Science of The Total Environment 394 (1), 197-2005. http://dx.doi.org/10.1016/j.scitotenv.2008.01.040.

González-Ramírez, L., Galicia, L., Gómez-Mendoza L., 2007. El efecto de El Niño (ENSO) en la presencia de incendios forestales extremos (The effect of El Niño (ENSO) in the presence of extreme wildfires). Sevilla-España, Wildfire, 1-13.

Grifin, A.M., 1981. Mathematical model for forest fires. University of Tomsk, Russia.

Haigh, J.D., 2007. The Sun and the Earth's climate. Living Rev. Sol. Phys. 4 (2). http://dx.doi.org/10.12942//rsp-2007-2.

Hathaway, D.H., 2010. The Solar Cycle. Living Rev. Solar Phys. 7 (1). http://www.livingreviews.org/lrsp-2010-1.

Hodell, D.A., Brenner, M., Curtis, J.H., Guilderson, T., 2001. Solar forcing of drought frequency in the Maya lowlands. Science 292 (5520), 1367-1370. http://dx.doi.org/ 10.1126/science.1057759.

Juárez-Orozco, S., Cano-Santana, Z., 2007. El cuarto elemento y los seres vivos. Ecología del fuego (The fourth element and living beings. Ecology of fire). Ciencias 85, 4-12.

Kitzberger, T., Swetnam, T., Veblen, T., 2001. Inter-hemispheric synchrony of forest fires and the El Niño-Southern Oscillation. Global Ecology and Biogeography 10 (3), 315-326. http://dx.doi.org/10.1046/j.1466-822X.2001.00234.x.

Kopp, G., Lawrence G., Rottman, G., 2005. The total irradiance monitor (TIM): Science Results. Solar Physics 230, 129-139.

Kopp, G., Lean, J.L., 2011. A new, lower value of total solar irradience: Evidence and climate significance. Geophys. Res. Lett. 38 (1), L01706.

http://dx.doi.org/10.1029/2010GL045777.

Mendoza, B., Velasco, V., Jáuregui, E., 2006. A study of historical droughts in southeastern Mexico. Journal of Climate 19, 2916-2934. http://dx.doi.org/10.1175/JCLI3726.1. 
Mendoza, B., García-Acosta, V., Velasco, V., Jáuregui, E., Díaz-Sandoval, R., 2007.

Frequency and duration of historical droughts from the 16th to the 19th centuries in the Mexican Maya lands, Yucatan Peninsula. Climatic Change 83, 151-168.

http://dx.doi.org/10.1007/s10584-006-9232-1

Milenkovic, M., Radovanovic, M., Ducic, V., 2011. The Impact of Solar Activity on the Greatest Forest Fires of Deliblatska peščara (Serbia). Forum geografic. Studii şi cercetări de geografie şi protecţia mediului 10 (1), 107-116.

http://dx.doi.org/doi:10.5775/fg.2067-4635.2011.026.i.

Nordemann, D.J.R., Rigozo, N.R., Souza Echer, M.P., Echer, E., 2008. Principal components and iterative regression analysis of geophysical series: Application to Sunspot number (1750-2004). Computers \& Geosciences 34 (11), 1443-1453.

http://dx.doi.org/10.1016/j.cageo.2007.09.022

Rampelotto, P.H., Rigozo, N.R., da Rosa, M.B., Prestes, A., Frigo, E., Souza Echer, M.P., Nordemann, D.J.R., 2012. Variability of rainfall and temperature (1912-2008) parameters measured from Santa Maria $\left(29^{\circ} 41^{\prime} \mathrm{S}, 53^{\circ} 48^{\prime} \mathrm{W}\right)$ and their connections with ENSO and solar activity. Journal of Atmospheric and Solar-Terrestrial Physics 77, 152-160.

http://dx.doi.org/doi:10.1016/j.jastp.2011.12.012

Salby, M.L., 1995. Fundamentals of atmospheric physics. 61, Academic Press.

Scafetta, N., West, B.J., 2005. Estimated solar contribution to the global surface warming using the ACRIM TSI satellite composite. Geophys. Res. Lett. 32 (18).

http://dx.doi.org/10.1029/2005GL023849.

Scafetta, N., West, B.J., 2007. Phenomenological reconstructions of the solar signature in the Northern Hemisphere surface temperature records since 1600. J. Geophys. Res. 112 (D24). http://dx.doi.org/10.1029/2007JD008437 D24S03.

Scafetta, N., West, B.J., 2008. Is climate sensitive to solar variability?. Phys. Today 61 (3), 50. http://dx.doi.org/10.1063/1.2897951

Scafetta, N., 2009. Empirical analysis of the solar contribution to global mean air surface temperature change. Journal of Atmospheric and Solar-Terrestrial Physics 71 (17-18), 1918-1923. http://dx.doi.org/10.1016/j.jastp.2009.07.007

Scafetta, N., 2010. Empirical evidence for a celestial origin of the climate oscillations and its implications. Journal of Atmospheric and Solar-Terrestrial Physics 72, 951-970. http://dx.doi.org/10.1016/j.jastp.010.04.015. 
Scafetta, N., Willson, R.C., 2014. ACRIM total solar irradiance satellite composite validation versus TSI proxy models. Astrophysics Space Sci. 350 (2), 421-442. http://dx.doi.org/10.1007/s10509-013-1775-9.

Shuyang, W. Guoyu, S., 1994. Study on relations between heavy-disaster-period of forest fire activity and sunspot activity, SSTA. J. Northeast For. Univ. 15 (4), 27-32. http://dx.doi.org/10.1007/BF02842967.

Soon, W., Velasco Herrera, V.M., Selvaraj, K., et al., 2014. A review of Holocene solarlinked climatic variation on centennial to millennial timescales: Physical processes, interpretative frameworks and a new multiple cross-wavelet transform algorithm. Earth Sci. Rev. 134, 1-15. http://dx.doi.org/10.1016/j.earscirev.2014.03.003.

Southworth, R.W, 1960. Autocorrelation and spectral analysis. Mathematical methods for digital computer. NY, John Wiley \& Sons, Inc.

Souza Echer, M. P., Echer, E., Nordemann, D. J., et al., 2008. Wavelet analysis of a centennial (1895-1994) southern Brazil rainfall series (Pelotas, 31 ${ }^{\circ} 46^{\prime} 9$ "S, 52 20'33"W). Climatic Change 87 (3-4), 489-497. http://dx.doi.org/10.1007/s10584-007-9296-6. Souza Echer, M.P., Echer, E., Rigozo, N.R., Brum, C.G.M., Nordemann, D.J.R., Gonzalez, W.D., 2012. On the relationship between global, hemispheric and latitudinal averaged air surface temperature (GISS time series) and solar activity. Journal of Atmospheric and Solar-Terrestrial Physics 74, 87-93. http://dx.doi.org/10.1016/j.jastp.2011.10.002.

Suykens, J.A.K., Gestel, T.V., De Brabanter, J., De Moor, B., Vandewalle, J., 2005. Least Squares Support Vector Machines. World Scientific, in press, ISBN 981-238-151-1.

Torrence, C., Compo, G., 1998. A practical guide to wavelet analysis. Bull. American Meteor. Soc. 79 (1), 61-78.

http://dx.doi.org/10.1175/1520-0477(1998)079<0061:APGTWA>2.0.CO;2.

Torres Rojo, J., 2004. Estudio de tendencias y perspectivas del Sector Forestal en América Latina (Study of trends and prospects of forestry in Latin America). Documento de Trabajo. Informe Nacional México, Secretaría de Medio Ambiente y Recursos Naturales de México (Semarnat), Organización de las Naciones Unidas para la Agricultura y la Alimentación FAO. ESFAL/N/2.

Vapnik, V., 1998. Statistical Learning Theory. 1. New York, Willey. ISBN-13: 9780471030034. 
Velasco, V. M., Mendoza, B., 2008. Assessing the relationship between solar activity and some large scale climatic phenomena. Advances in Space Research. 42(5), 866-878. http://dx.doi.org/10.1016/j.asr.2007.05.050

Velasco Herrera, V.M, Mendoza, B., Velasco Herrera, G., 2015. Reconstruction and Prediction of the Total Solar Irradiance From the Medieval Warm Period to the 21st century. New Astronomy 34, 221-233. http://dx.doi.org/10.1016/j.newast.2014.07.009

Willson, R.C., Mordvinov, A.V., 2003. Secular total solar irradiance trend during solar cycles 21-23. Geophys. Res. Lett. 30 (5), 1199. http://dx.doi.org/10.1029/2002GL016038.

Xodakov, B.E., Jarikova M.B., 2011. Forest fires, Research and Methods. Jerson, Ukraine.

Yousef, S.M., 2000. The solar Wolf-Gleissberg cycle and its influence on the Earth. Proceedings of the international conference on the environmental hazards mitigation, Cairo University, Cairo University, Egypt, 267-293. 


\section{Figure Captions}

Figure 1. Mexican vegetation: savanna (purple), middle jungle (pink), cedar and pine forest (green), pastureland (brown) and shrubbery (orange).

Figure 2. Mexican forest fires in the highest drought months. The blue line is for 2007, and the black line is for the years 1998-2006.

Figure 3. Wavelet transform analysis of Mexican forest fires (black bars in the top panel) between 1970 and 2014. The wavelet power spectrum density (PSD) is illustrated in the central panel. Meaningful periodicities (5\% significance level against red noise) must be inside the cone of influence (COI, curved black line). The region of the wavelet spectrum outside of which the edge effects become important and might distort the PSD is shown in a lighter shade. The global wavelet is shown in the left panel; the dotted lines are the rednoise level. The color bar (RGB) shows the PSD in arbitrary units. The red (R) shows the highest PSD and the blue colour, the lowest PSD.

Figure 4. Wavelet transform of the Niño-Southern Oscillation time series (black lines) between 1970 and 2014; the wavelet powers are shown in the central panel. The quantities shown in all panels are as described in Fig. 3.

Figure 5. Wavelet analysis of Total Solar Irradiance time series (black lines in the top panel) from 1970 to 2014 . The wavelet powers are illustrated in the central panel. The quantities shown in all panels are as described in Fig. 3.

Figure 6. Results of the multivariable cross wavelet analysis of the Niño-Southern Oscillation, Total Solar Irradiance and Mexican forest fires. The orientation of the arrows shows the relative phasing of the time series for each timescale; arrows at $0^{\circ}$ (pointing to the right) indicate that both time series are completely positively correlated (in phase), and arrows at $180^{\circ}$ (pointing to the left) indicate that they are completely negatively correlated $\left(180^{\circ}\right.$ out of phase). Both of these cases imply a linear relationship between the considered phenomena; non-horizontal arrows indicate an out-of-phase situation and a more complex non-linear relationship. This result seeks to establish a baseline of oscillatory timescales common to all of the time series analyzed here, in order to allow a better interpretation of the physical bases and processes involved in forest fires. We also added information regarding the global phase (right panel) averaged over time and the instantaneous phase (black curve) and amplitude (blue curve) for the 10-year periodicity (bottom panel). The result shows a moderate in-phase and linear relationship between Mexican forest fires, the Niño-Southern Oscillation and Total Solar Irradiance, in addition to the highly timedependent nature of the amplitude of the decadal scale variation. 
Figure 7. Mexican forest fires - the black points indicate the forest fire locations from 2005 to 2014 using MODIS Data.

Figure 8. Spatial distribution of Mexican forest fires (longitude).

Figure 9. Spatial distribution of Mexican forest fires (latitude).

Figure 10. Decadal variability of the Total Solar Irradiance (grey area) and Mexican forest fires (blue dotted line) from 1970 to 2014 and its estimate for between 2015 and 2030. 


\section{Table Captions}

Table 1. Affected Mexican areas by forest fires during 1998

\begin{tabular}{|l|l|l|l|}
\hline Mexican State & Number of fires & Affected area & Affected area/ \\
& & (ha) & Number of fires \\
& & & (ha/number \\
& & & \\
\hline México & 1322 & 25199 & 19.07 \\
\hline Distrito Federal & 1877 & 5479 & 2.92 \\
\hline Michoacán & 1609 & 23304 & 14.32 \\
\hline Chihuahua & 582 & 16890 & 29.02 \\
\hline Puebla & 462 & 17885 & 38.71 \\
\hline Veracruz & 459 & 9334 & 20.34 \\
\hline Guerrero & 10084 & 17457 & 38.54 \\
\hline Tlaxcala & 453 & 8582 & 20.15 \\
\hline Hidalgo & 426 & 12470 & 32.90 \\
\hline Morelos & 379 & 2311 & 1.08 \\
\hline Subtotal & & & \\
\hline
\end{tabular}


Table 2. Main periodicities with their uncertainty of the Niño-Southern Oscillation, Mexican Forest Fires and Total Solar Irradiance time series

\begin{tabular}{|l|c|c|c|}
\hline Periodicities & El Niño-Southern & Total Solar & Mexican \\
\hline Mid-term & Oscillation & Irradiance & Forest Fires \\
\hline periodicities & $2.60 \pm 0.5$ & $1.99 \pm 0.5$ & $2.45 \pm 0.6$ \\
\hline Q years cycle & $1.50 \pm 0.5$ & $1.03 \pm 0.6$ & \\
\hline 5 years cycle & $3.89 \pm 0.75$ & $3.27 \pm 0.71$ & \\
(Quasi-quinquennial) & & & $5.83 \pm 1.35$ \\
\hline Decadal & & $5.51 \pm 0.90$ & \\
\hline
\end{tabular}




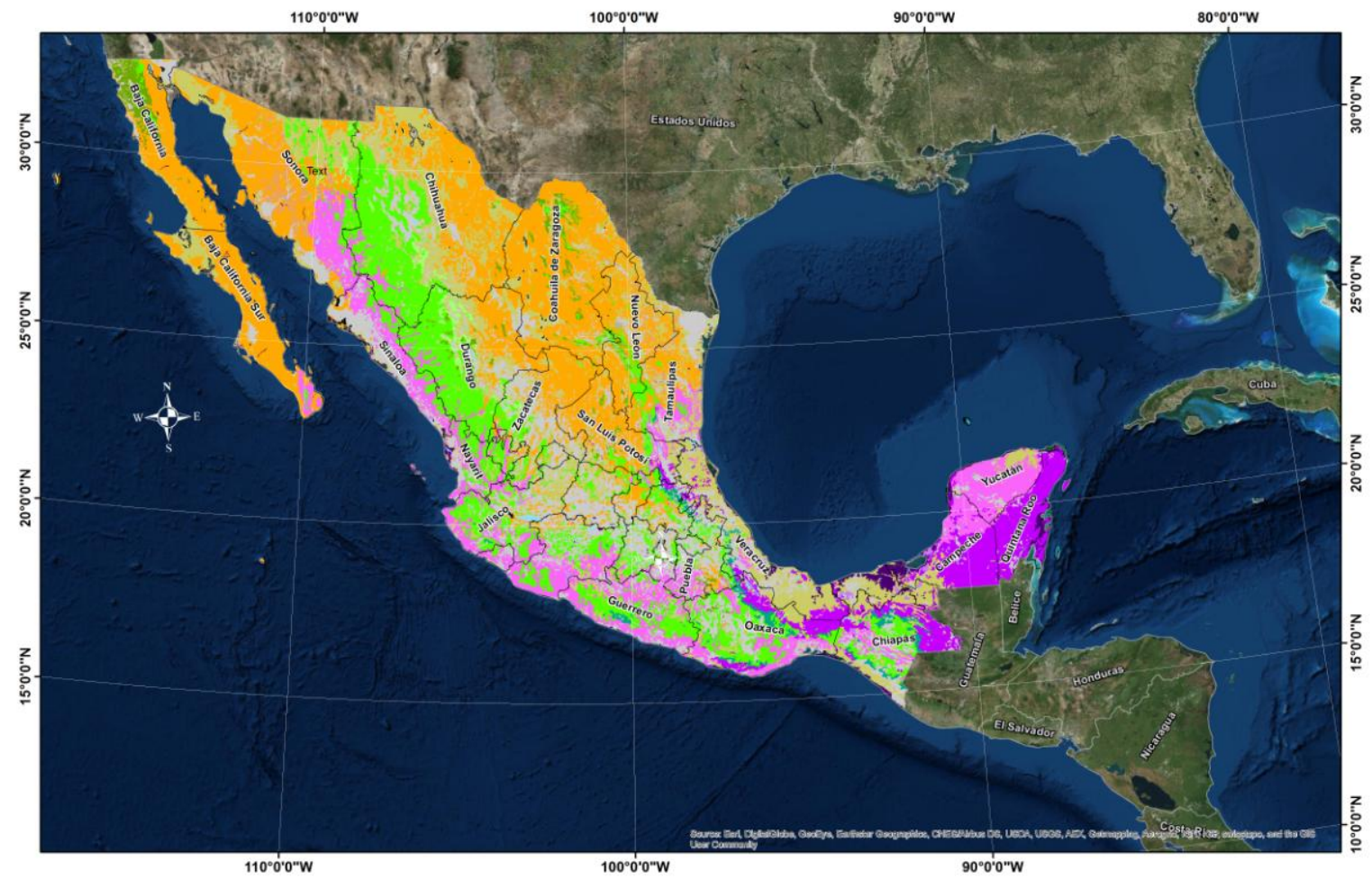




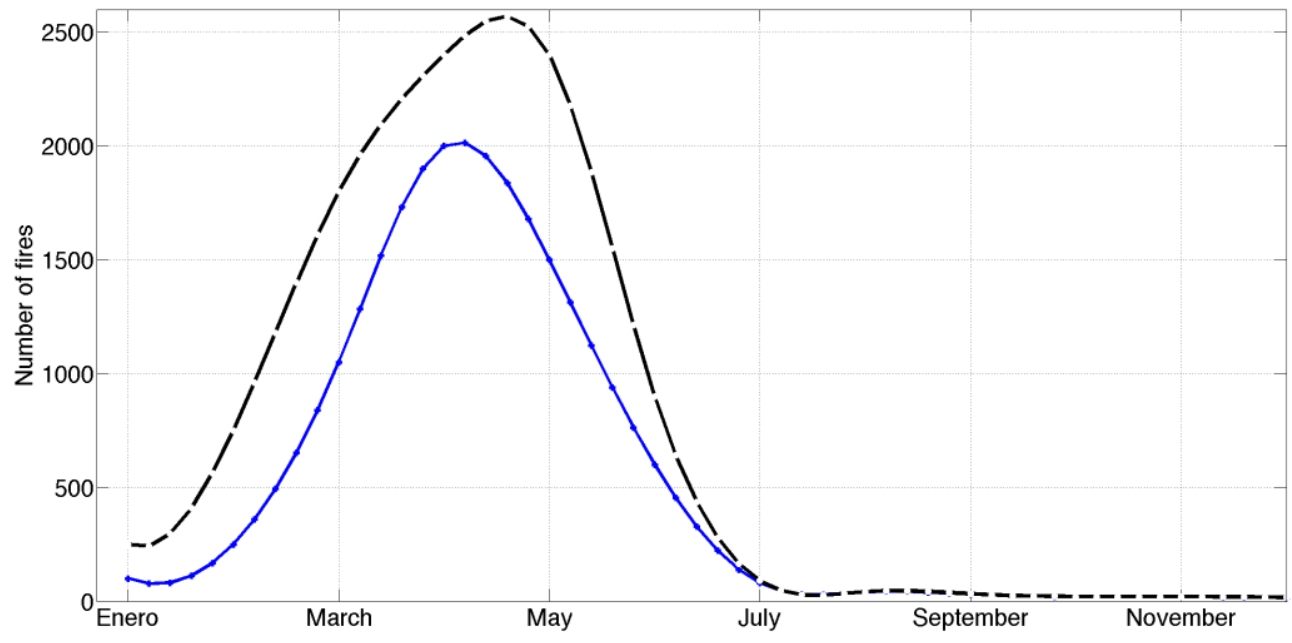




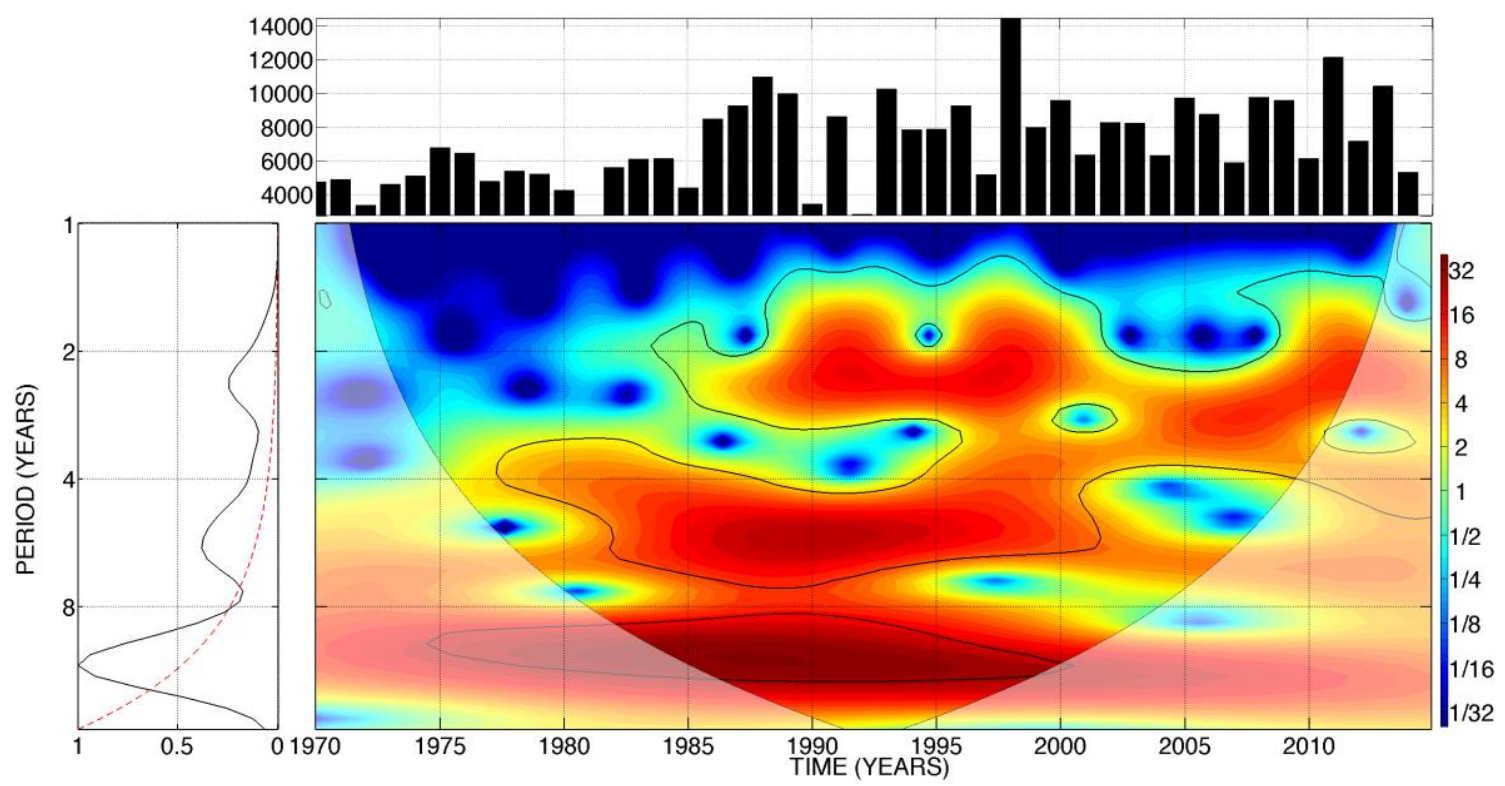




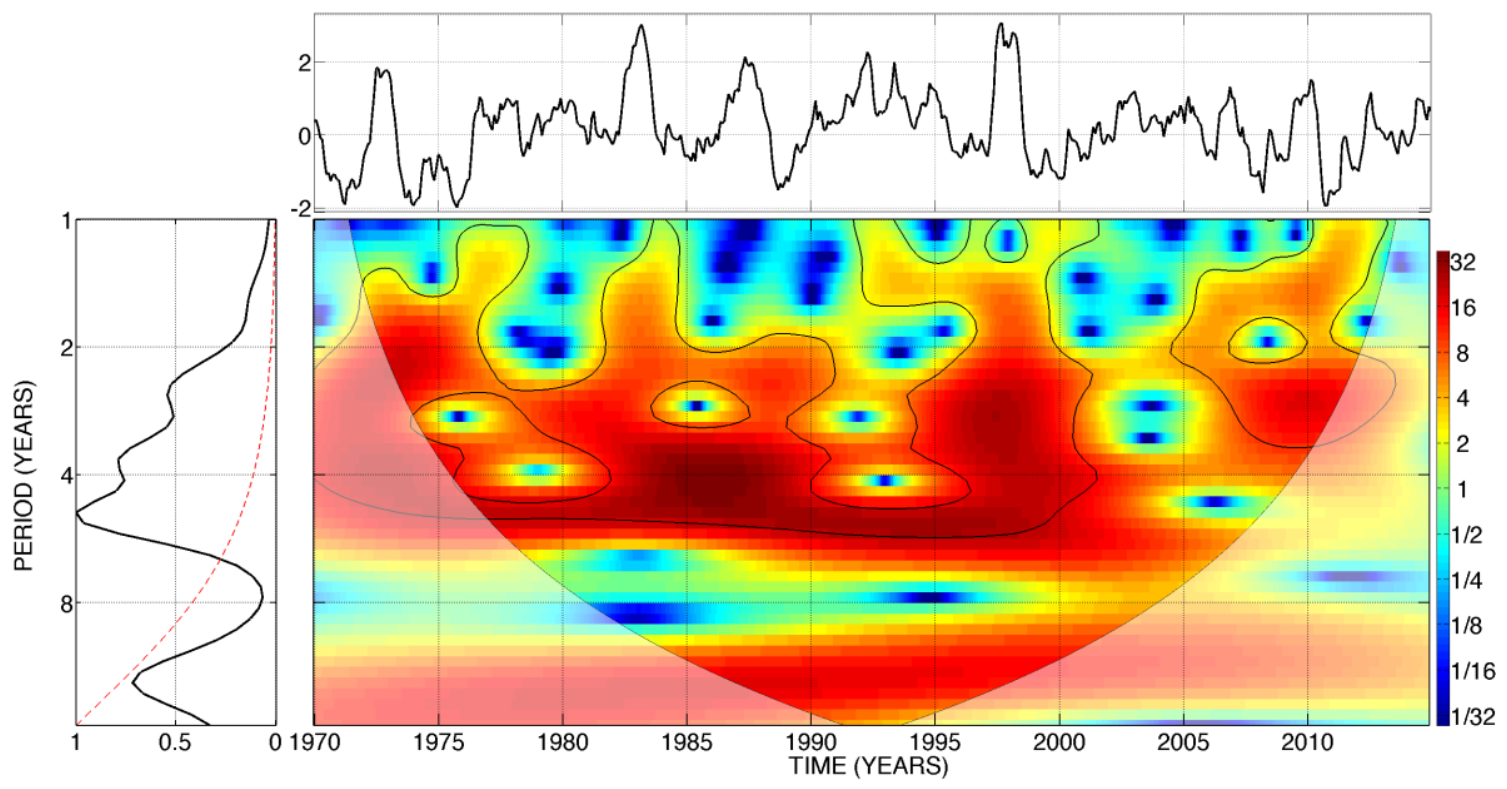




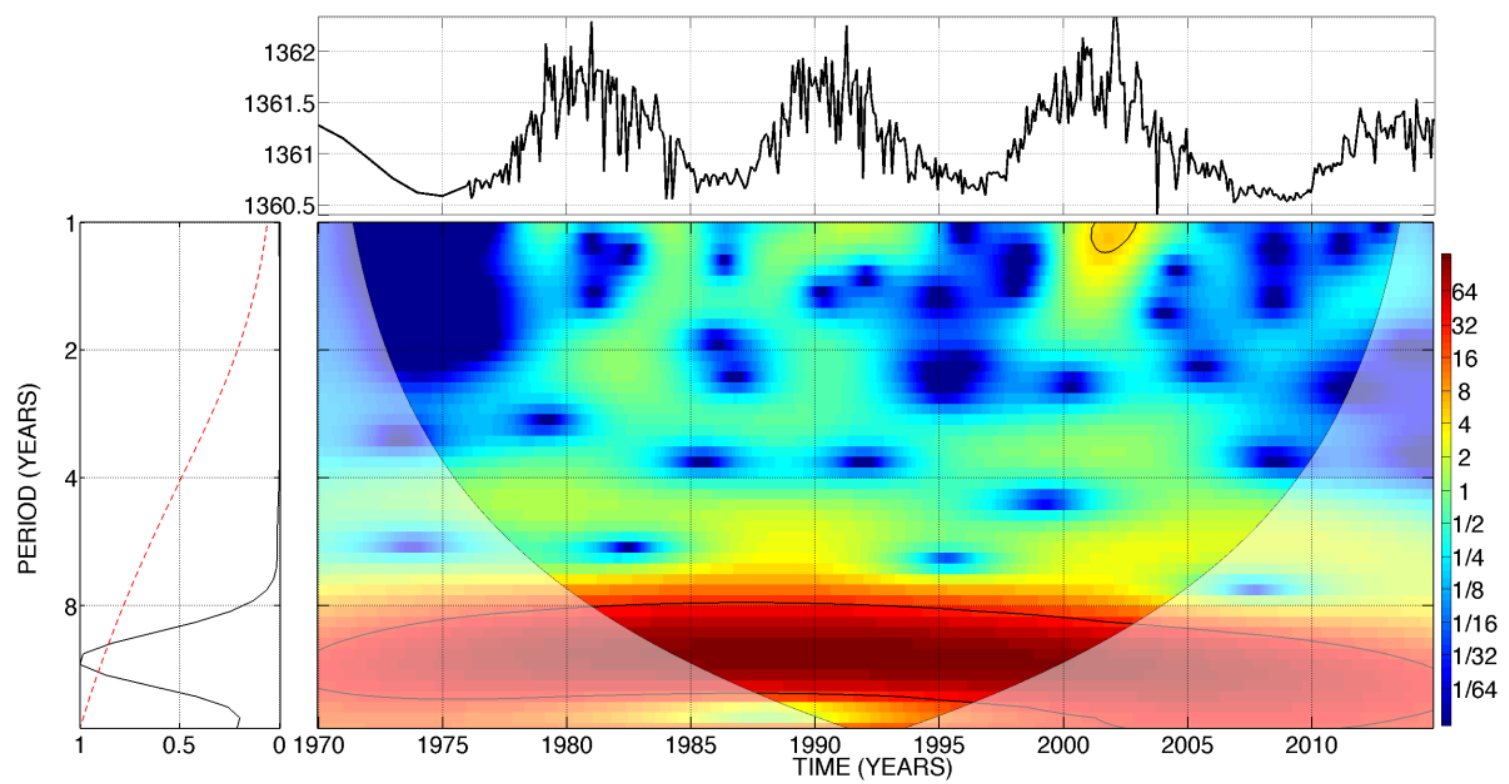




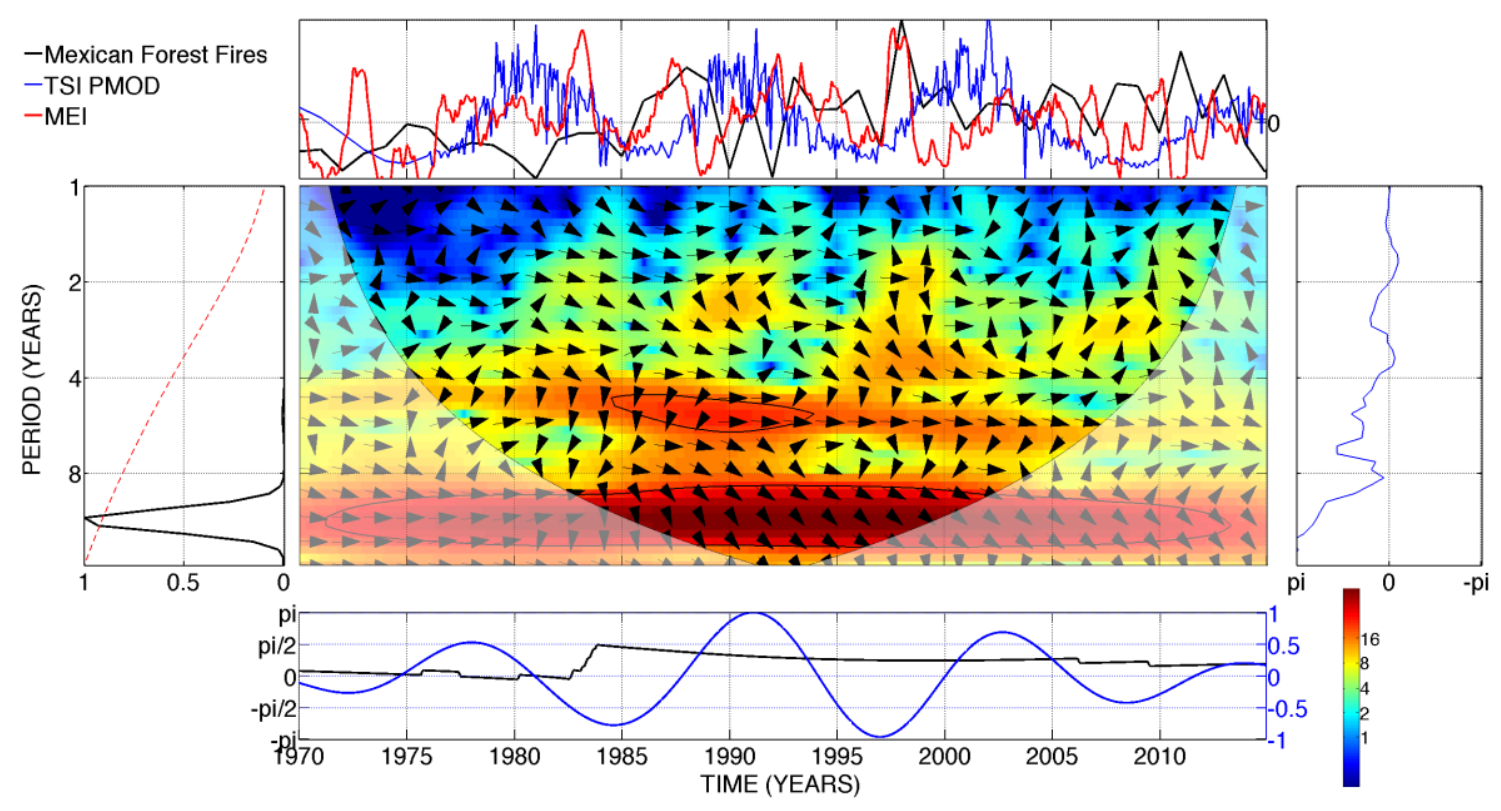




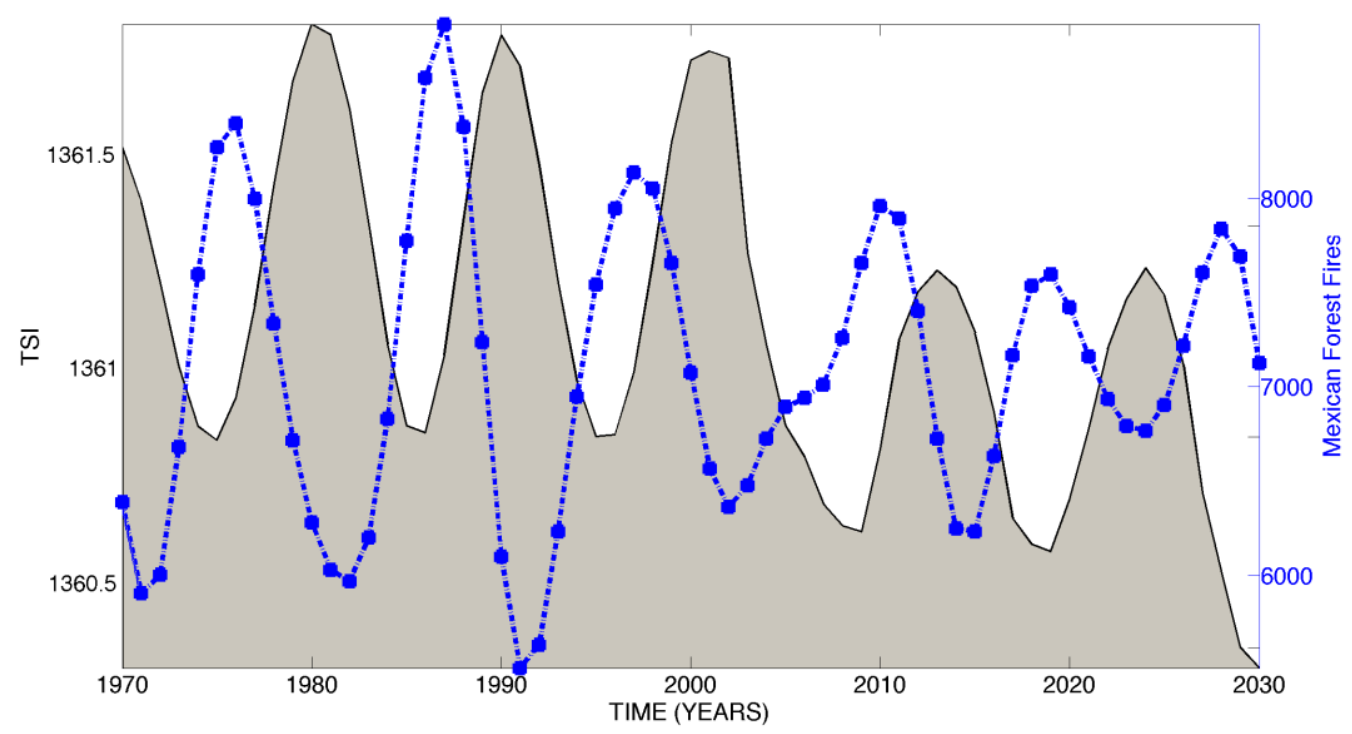




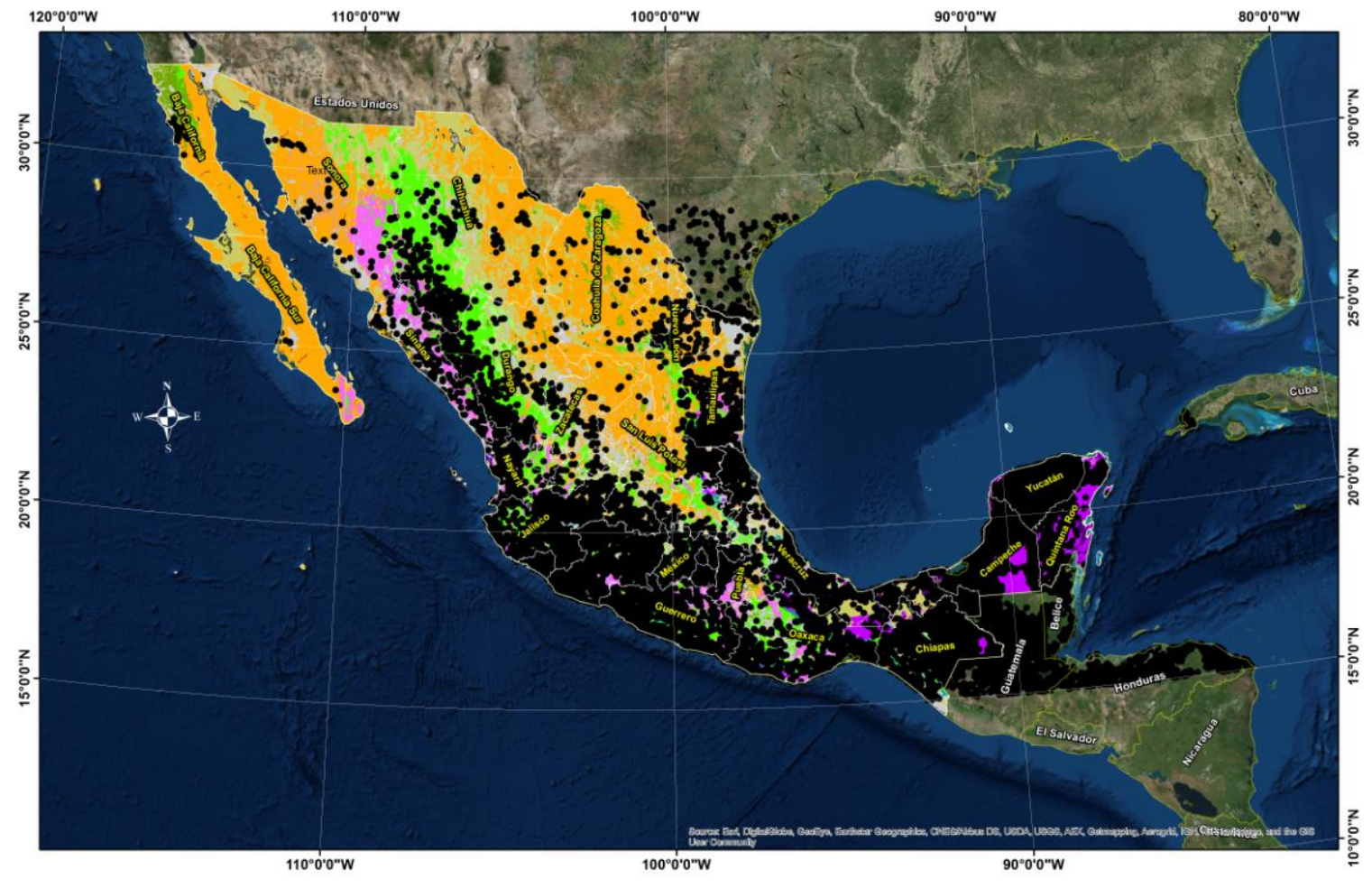



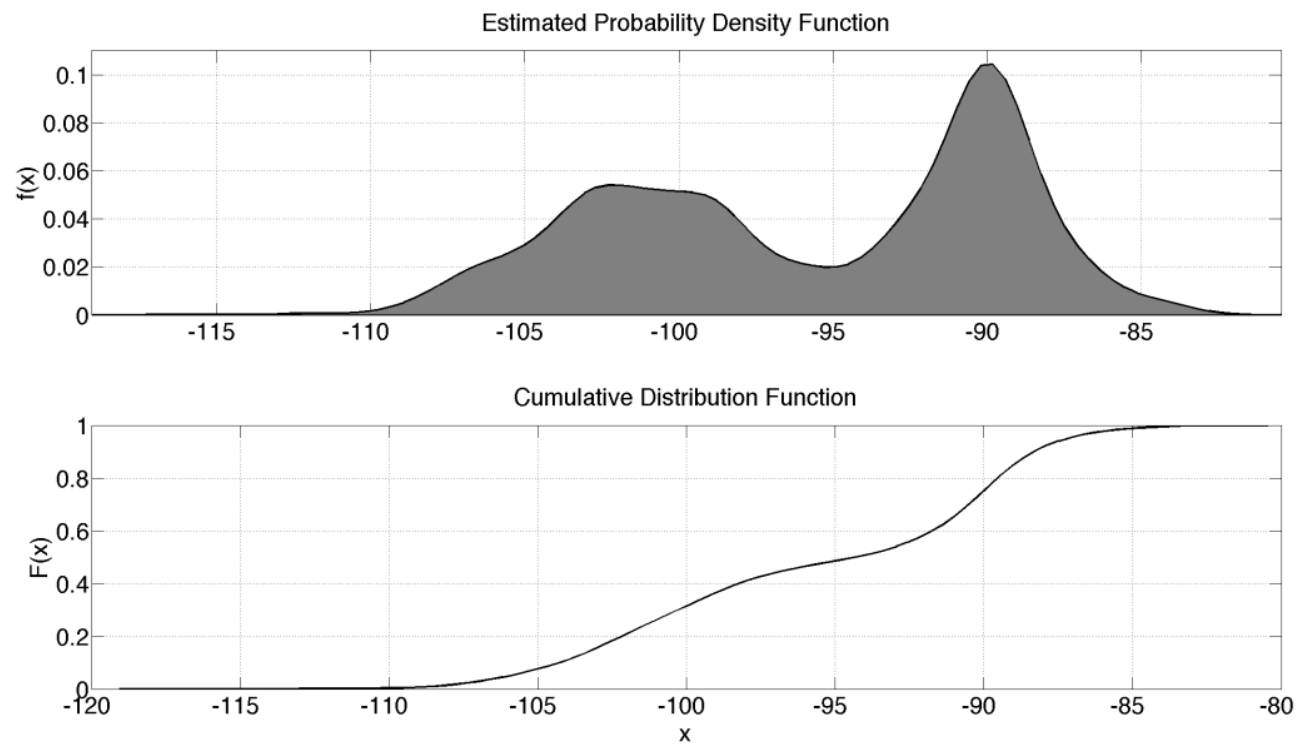

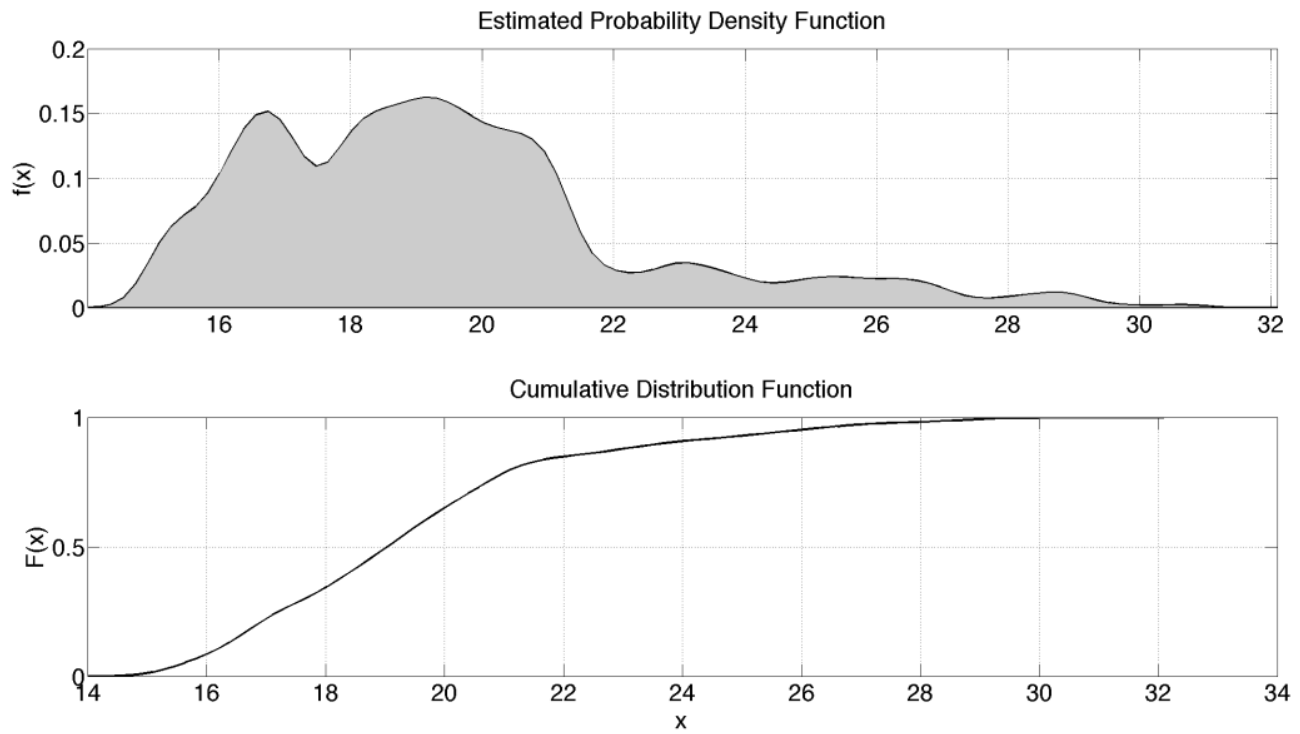